\title{
A Test for Crystalline Lens Biocompatibility
}

\author{
LIAQUAT ALLARAKHIA, ${ }^{*}$ MICHAEL PUUMULA, RICHARD L. LINDSTROM \\ Minneapolis, USA
}

\begin{abstract}
Summary
The current use of monkeys for testing intraocular fluids and viscoelastic materials is being questioned because of the decreasing availability and increasing cost of these scarce animals. The rabbit is an inexpensive, readily available, and convenient animal which might provide an alternative model for this purpose. In this study we have outlined the lens changes (clefts or vacuoles) that are observed in the New Zealand white rabbit as a result of toxicity to intraocular test materials. We used two viscoelastic agents, $1 \%$ sodium hyaluronate-Healon ${ }^{\circledR}$ and $2 \%$ carboxymethylcellulose, and balanced salt solution to evaluate the efficacy and reproducibility of lens changes in this test study. The lens changes in each case were reproducible and could easily be graded. When used in concert with other tests, this new test can help in the preliminary evaulation of an ophthalmic material before its final clinical use in humans.
\end{abstract}

Standard tests have been established for ocular testing of materials applied topically in animals with observation for changes in the lids, conjunctiva, cornea, iris and anterior chamber. Friedenwald et al $^{1}$ investigated the toxic effects of various acidic and basic topical solutions in rabbits as early as 1944 , recording their observations in a numerical grading system. McDonald et al ${ }^{2,3}$ similarly suggested the use of a comprehensive grading system for changes to conjunctiva, cornea, and iris; subsequently, the McDonald-Shadduck scoring system has been widely used for testing both topical and intraocular materials. Several other studies have also been carried out to test intraocular fluids and drugs and their effects on the cornea, particularly the endothelium. ${ }^{4-6}$

None of the grading or scoring systems presently in use include any effects on the crystalline lens. Haimann et al reported a study which they conducted to elucidate cataractous changes following vitreous cavity perfusions with two different irrigating solutions. However, there are no reports of lens changes following the infusion of solutions or drugs into the anterior chamber. With the current increase in the development and use of improved ophthalmic irrigation fluids and viscoelastic agents, it is appropriate to develop reliable, simple, and economical methods for screening these materials for potential intraocular toxicity. It is also appropriate to investigate and evaluate animal models other than primates for the preliminary trial of ophthalmic irrigating fluids and solutions.

Materials injected into the anterior segment of an eye must be non-toxic to ocular tissues including the corneal endothelium, trabecular meshwork, iris, and lens. We have developed, and describe in this article, a new

From: Department of Ophthalmology, University of Minnesota, Minneapolis, Minnesota.

*Now with the Department of Research and Development, Visitec Company, Sarasota, Florida.

Supported in part by an unrestricted grant from Research to Prevent Blindness, Inc.

Correspondence to: Richard L. Lindstrom, M.D., Department of Ophthalmology, University of Minnesota, Box 493 Mayo Memorial Building, 516 Delaware Street S.E., Minneapolis, MN 55455, USA, 
test in which the lens biocompatibility of an intraocular test material is evaluated by injection into the anterior chamber of New Zealand white rabbits. We have found that the lens changes in the New Zealand white rabbit are a very sensitive and consistent indicator of the toxicity to intraocular test materials.

\section{Materials and Methods}

The studies described in this article were carried out in accordance with the Association for Research and Vision and Ophthalmology (ARVO) resolution on the use of animals in research. New Zealand white rabbits of either sex, weighing $2.5-3.5 \mathrm{~kg}$ were used in this test study. The anterior segments of both eyes were carefully examined by biomicroscopy; if lens opacities, signs of inflammation, corneal scarring or vascularization were noted, these rabbits were excluded from the study. Preliminary investigations had shown that some normal rabbits, especially those weighing less than $3 \mathrm{~kg}$, had tiny 'bleb' defects on the lens surface which gave false positive or unduly exaggerated reactions on exposure to the test material. Rabbits with such changes or other anterior segment abnormalities were also excluded from the study.

The rabbits were anaesthetized using intramuscular xylazine ( $1 \mathrm{mg} / \mathrm{kg}$ body weight) and ketamine hydrochloride $(5 \mathrm{mg} / \mathrm{kg}$ body weight). The pupils were dilated topically using one drop each of cyclopentolate $\mathrm{HC} 1$ $1 \%$, and phenylephrine $\mathrm{HCl} 2.5 \%$. A Barraquer wire lid speculum was inserted to obtain adequate exposure and each eye was operated upon sequentially. A 25 guage butterfly outflow needle was inserted into the anterior chamber at the 10 o'clock position, $0.3 \mathrm{~mm}$ anterior to the limbus, avoiding trauma to conjunctival vessels and subsequent bleeding (Fig. 1). The outflow needle remained capped until injection of the test material was commenced so as to avoid anterior chamber collapse and the possibility of trauma to the lens, iris, and/or cornea. Breakdown of the blood aqueous barrier and a secondary inflammatory response were also easily controlled by paying particular attention to this step. An outflow channel was essential so that the injected test material could displace aqueous humour from the eye, maintaining an adequate anterior chamber and intraocular pressure.

A 27-gauge hypodermic needle mounted on a $1 \mathrm{ml}$ tuberculin syringe containing the test solution was similarly inserted at the 2 o'clock position, $0.3 \mathrm{~mm}$ anterior to the limbus. A $0.2 \mathrm{ml}$ injection of the test material into the anterior chamber was found to be sufficient and excess fluid easily exited through the outflow needle. On completion, both needles were carefully removed, avoiding further trauma. The entire surgical procedure and follow-up observation for lens changes were carried out using a table mounted surgical binocular microscope (Wildt, Switzerland), with good coaxial illumination. The period immediately following the injection was important. The lens was carefully observed using high magnification (X 20-40) every five minutes for the first 30 minutes, and then at 30 minute intervals for the next six hours. The lens was subsequently examined at 24 and 48 hours and every week for the next two months. The grading of the lens changes was determined by observing the crystalline lens for a period of six hours from the time of initial injection. The appropriate grade was then assigned depending on the various changes noted. To obtain an accurate grading it was important that the lens was observed at regular intervals as outlined above.

To evaluate the efficacy and reproducibility of this test study two test materials were used.

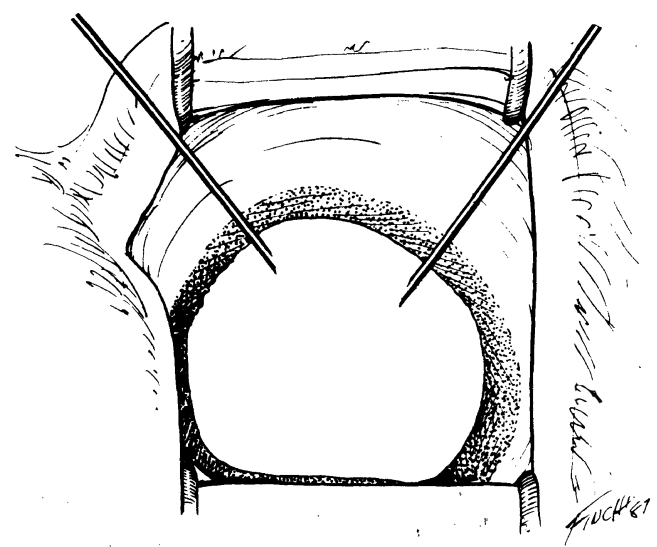

Fig. 1. Needle channels into anterior chamber; one for delivery of test sample and the other for exit of aqueous humour or excess test material. 
Sodium hyaluronate (Healon ${ }^{\circledR}$ ) and carboxymethycellulose $2 \%$ (an experimental viscoelastic agent) were injected into opposite eyes of five rabbits as outlined above. Healon is a widely used and commercially available viscoelastic agent. The carboxymethylcellulose is a widely used topical ophthalmic solution, however, it has not been used as an intraocular viscous solution. This material was prepared as a viscoelastic agent for this study as recommended by Fechner for hydroxypropylmethylcellulose. ${ }^{8}$ The material was prepared under strict aseptic conditions to obtain samples that were free from bacteria, pyrogens, toxins and other contaminants. A buffered balanced salt solution was used as solvent, to maintain physiological $\mathrm{pH}$ and osmolarities in the test samples.

To determine the role that may be played by fluctuations in $\mathrm{pH}$ and osmolarity in causing lens changes, we adapted the above technique for continuous infusion experiments with balanced salt solution (B.S.S., Alcon, Fort Worth, TX). The $\mathrm{pH}$ of balanced salt solution was adjusted to the desired level by adding sodium hydroxide or hydrochloric acid, but maintaining the osmolarity in the normal range. Likewise the osmolarity was adjusted by adding distilled water or sodium chloride but maintaining the $\mathrm{pH}$ unaltered. These solutions were prepared under a laminar flow hood using strict aseptic procedures and aliquots of $100 \mathrm{mls}$ were sealed into clean, sterile infusion bottles. Each sample was continuously infused into the anterior chamber of New Zealand white rabbits for $1 \mathrm{~h}$ using gravity infusion with the bottle elevated to 24 inches above the surgical eye level. Each infusate was tested in one eye each of five rabbits. The crystalline lens was carefully observed during and immediately after the procedure and any lens changes such as those described in the grading system and other changes including corneal oedema, iris injection/ ischaemia, and anterior chamber inflammation was appropriately recorded.

\section{Results}

\section{Grading System}

A spectrum of lens changes were noted depending on the viscoelastic test material injected. These varied from subtle lenticular microvacuoles and early observation of a suture line lasting a few minutes, to gross vacuoles, markedly visible suture lines, and lens swelling which persisted for two months or longer. The grade obtained following injection of test material was assigned after careful observation for a period of six hours from time of initial injection. It is important that the lens is observed for the entire six hour period at intervals as specified in the methods section to avoid any errors in grading. The following grading scheme was adopted.

Grade 0 Normal

No lens changes were visible.

Grade 1 Microvacuoles (Fig. 2)

These became apparent within two to three minutes after test sample injection. Clusters of microvacuoles were located in a crescentic fashion just inside the pupillary zone giving an impression of microprecipitation on the lens surface. These disappeared within ten minutes.

Grade 2 Faint Suture Line Appearance (Fig. 3)

The suture line appeared within the first or second minute, associated with microvacuoles as noted in Grade 1. The suture line was almost linear and occasionally was ' $\mathrm{Y}$ ' shaped with one of the arms shorter than the other. These changes

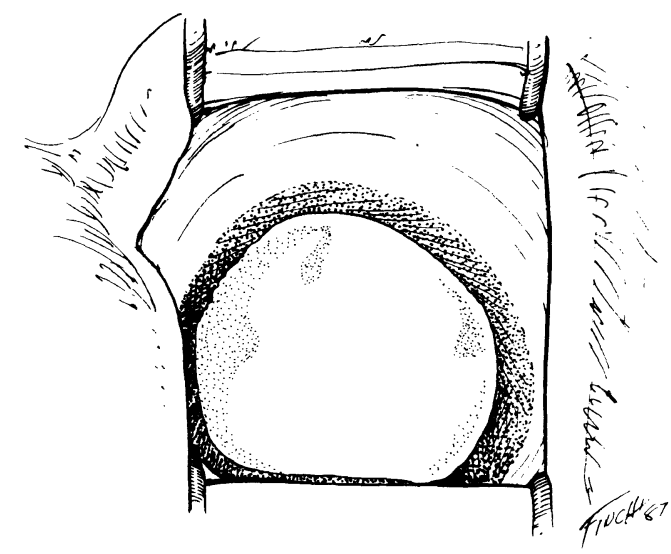

Fig. 2. Microvacuoles located peripherally around the pupil-lens junction. Note the microprecipitation like appearance. 


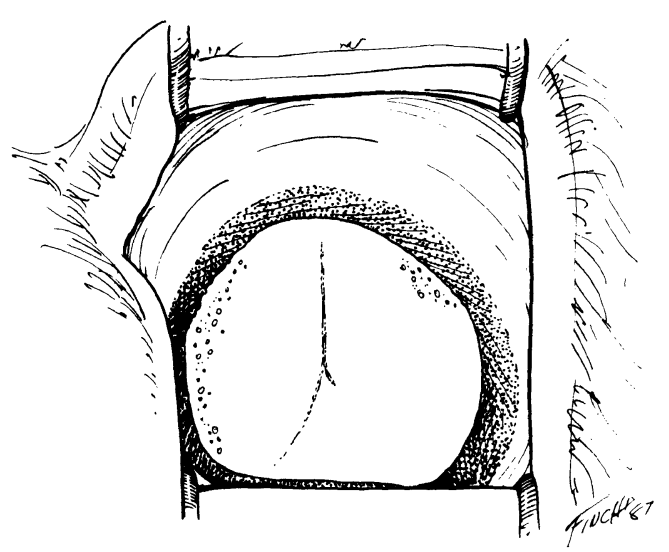

Fig. 3. Faint suture line located centrally.

disappeared within thirty
minutes.
Moderate Suture Line Appear-
ance (Fig. 4)
The suture line was more promi-
nent and appeared within the
first minute of injection and was
visible for up to two hours.
Microvacuoles may have been
present and, in addition, some
of these may coalesce over a
period of twenty to thirty min-
utes to form larger vacuoles.

Grade $4 \quad$ Marked Suture Line with Vacuoles

The suture line was much more intense and appeared within seconds of the test sample injec-

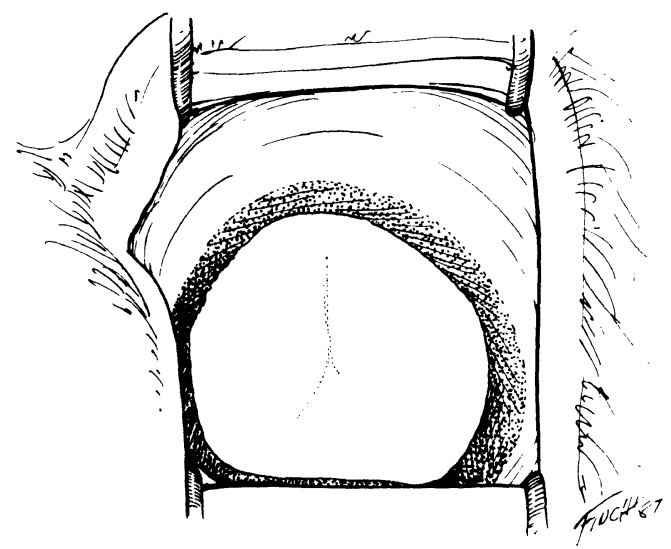

Fig. 4. Moderate suture line and peripheral macrovacuoles. tion. This was followed shortly by small vacuoles, coalescing to form larger ones which were easily seen. In addition, there was minimal swelling of the crystalline lens. The suture line lasted up to four hours while some of the vacuoles were present for several days or weeks.

The suture lines, normally not visible in the rabbit lens, were seen as subcapsular or deep cortical structures and located centrally in almost a linear fashion. The micro and macrovacuoles were localized in a peripheral crescentic or circular fashion just inside or at the pupil-lens junction; however, they were occasionally noted more centrally.

\section{Viscoelastic Test Samples}

Grading of the lens changes following anterior chamber injection of the two viscoelastic agents are shown in Table I. In each case Healon was found to be non toxic to the crystalline lens compared to carboxymethylcellulose which showed lens changes of grade 2-3. Grade 4 changes were only seen when the $\mathrm{pH}$ and osmolarity of carboxymethylcellulose were markedly altered to non-physiological levels.

\section{Balanced Salt Solution Infusions}

Table II shows the lens changes recorded following one hour continuous infusion with balanced salt solutions altered to various $\mathrm{pH}$ values. No lens changes were noted between pH 5.2 and 7.6 and minimal lens changes were noted beyond this range. However, iris and corneal changes were prominent particularly at the extremes of $\mathrm{pH}$ (below 5.2 and above

Table I. Viscoelsatic test samples and associated grade of lens changes

\begin{tabular}{lccc}
\hline Rabbit & Eye & Test materials & Lens grade \\
\hline Rabbit 1 & OD & Healon & 0 \\
& OS & carboxymethycellulose & 3 \\
Rabbit 2 & OD & Healon & 0 \\
& OS & carboxymethycellulose & 2 \\
Rabbit 3 & OD & carboxymethylcellulose & 3 \\
& OS & Healon & 0 \\
Rabbit 4 & OD & carboxymethylcellulose & 3 \\
& OS & Healon & 0 \\
Rabbit 5 & OD & Healon & 0 \\
& OS & carboxymethycellulose & 2 \\
\hline
\end{tabular}


Table II. BSS Infusions with $\mathrm{pH}$ alterations and its effect on the lens (osmolarity held constant)*

\begin{tabular}{lcll}
\hline$p H$ & Osmolarity & Lens changes & Other changes \\
\hline 4.1 & 316 & Grade 1, no vaculoes & Iris pale and ischaemic, \\
& & & cornealoedema +3, cells +2 \\
5.2 & 320 & Nil & Cornealoedema +2, cells +1 \\
6.0 & 317 & Nil & Nil \\
6.5 & 316 & Nil & Nil \\
7.0 & 327 & Nil & Nil \\
7.6 & 320 & Nil & Nil \\
8.1 & 317 & Grade 1, no vacuoles & Nil \\
9.2 & 324 & Grade 1, no vacuoles & Iris inj +2, corneal \\
& & & edema +2, cells +2 \\
10.1 & 320 & Grade 1 $1+$ microvacs & Iris inj +3, corneal \\
& & & edema +2, cells +3 \\
\hline
\end{tabular}

${ }^{*}$ Above results including lens and other changes are averages obtained by injecting into 5 rabbits (one eye each).

9.2). These changes included corneal oedema, iris congestion and ischaemia, and inflammatory cells in the aqueous humour.

The lens was much more sensitive to fluctuation in osmolarity than $\mathrm{pH}$, as shown in Table III. There was a relatively narrow range within which no lens changes were noted (270-331 mmol). Lens changes progressively increased outside this range (e.g. grade 3 at $84 \mathrm{mmol}$ and grade 4 at $505 \mathrm{mmol}$ ). There was also considerable congestion, oedema and superficial haemorrhages of the iris and cellular and fibrinous exudation in the anterior chamber at the extremes of osmolarity (below $155 \mathrm{mmol}$ and above $362 \mathrm{mmol}$ ).

\section{Discussion}

Materials injected into the anterior chamber at the time of surgery need to be evaluated carefully before being accepted for human use. The new lens test we have described is an accurate, sensitive and reproducible study for lens toxicity. The lens changes can be graded and can also be used as an adjunct to tests for other tissues, such as conjunctiva, cornea, iris and trabecular meshwork. It is important to note that this lens test together with other ocular tests can be carried out in the New Zealand white rabbit.

Several factors may be responsible for lens changes:

1. Alteration of $\mathrm{pH}$ beyond the physiologically tolerable range.

2. Osmolarity alterations; this seems to be more important in causing lens changes than variation of $\mathrm{pH}$. The 'safe' osmolarity range for the lens is very narrow.

3 . Electrical charge of the material.

4. Interaction with lens components such as inhibition of enzymes or alteration of membranes.

Table III. BSS infusions with osmolarity alteration and its effect on the lens ( $p H$ held constant)*

\begin{tabular}{|c|c|c|c|}
\hline Osmolarity & $p H$ & Lens changes & Other changes \\
\hline 84 & 7.1 & Grade 3 & $\begin{array}{l}\text { Iris inj }+3, \text { oedema } \\
\& \text { haem, cells }+3\end{array}$ \\
\hline 155 & 7.1 & $\begin{array}{l}\text { Grade } 2 \text { with micro } \\
\& \text { macro vacuoles }\end{array}$ & Iris inj +2 , cells +2 \\
\hline 235 & 7.1 & Grade 1 & Nil \\
\hline 270 & 6.9 & Nil & Nil \\
\hline 300 & 7.0 & Nil & Nil \\
\hline 300 & 7.0 & Nil & Nil \\
\hline 331 & 7.0 & Nil & Nil \\
\hline 362 & 7.0 & Grade 1 & Cells +1 \\
\hline 410 & 7.1 & $\begin{array}{l}\text { Grade } 2 \text {, suture line } \\
\text { no vacuoles }\end{array}$ & Iris inj +2 , cells +2 \\
\hline 505 & 7.0 & $\begin{array}{l}\text { Grade } 4 \text { plus } \\
\text { lens swelling }\end{array}$ & $\begin{array}{l}\text { Iris grossly inj }+4 \\
\text { pale \& oedematous, } \\
\text { cells }+4 \& \text { fibrin }\end{array}$ \\
\hline
\end{tabular}

${ }^{*}$ Above results including lens and other changes are averages obtained by injecting into 5 rabbits (one eye each). 
5. Mechanical properties of the material preventing easy exchange of lens nutrition, gases, and waste products.

6. Induction of anterior segment inflammation.

In our studies in which the two viscoelastic materials were tested we noted that Healon was, for all practical purposes, non-toxic to the lens while the carboxymethylcellulose was somewhat toxic. Our results indicate that $\mathrm{pH}$ and osmolarity, beyond the normal physiological range, could be potential causes for lens changes. However, the viscoelastic test materials we used in this study were isotonic and iso-osmolar and therefore it is more than likely that the chemical and phsyical properties and the various interactions of the carboxymethylcellulose may have led to the lens changes noted.

In our anterior chamber BSS infusion studies we observed that the crystalline lens was tolerant to wide fluctuations in $\mathrm{pH}$. No lens changes were noted between $\mathrm{pH} 5.2$ and 7.6, although outside this range minor lens changes were noted. The lens, however, was noted to be much more sensitive to fluctuations in osmolarity (Table III). It is important to note that although osmolarity may be an important cause of lens changes when using balanced salt solution, its effects may be different depending on the solutes used and the relative permeability of the lens membranes to those solutes. Therefore a direct comparison of the viscoelastic test materials with the balanced salt solution results cannot be made.

Edelhauser et al ${ }^{9}$ and Gonnering et $a l^{10}$ carried out similar studies but confined their experimental observations to changes in the cornea. In the Edelhauser et al in vitro study, ${ }^{9}$ rabbit and human corneas were perfused with balanced salt solution of varying osmolarities (200-500 mOsm). They observed corneal swelling when hyposmotic solutions were perfused, or thinning when hyperosmotic solutions were perfused. Specular microscopy, however, revealed no permanent corneal endothelial changes. In a study carried out by Gonnering et al corneas were similarly perfused using balanced salt solutions of varying $\mathrm{pH}$ (3.5-10.0). They reported corneal thickness and electron microscopic alterations when solutions outside the $\mathrm{pH}$ range of 6.5 to 8.5 were perfused. Direct cellular damage included disruption of junctional complexes leading to breakdown of the endothelial barrier function.

Our results indicate that the rabbit crystalline lens is much more sensitive to osmolarity fluctuations than the rabbit or human cornea. The chemical or physical structure of an injected material and its concentration may also lead to toxicity. In a study conducted by Killey et $a^{11}$ concentrations of $1-20 \%$ chondroitin sulfate were injected into the anterior chamber of rabbit eyes; lens vacuoles were noted in all cases in which chondroitin sulfate of $5 \%$ or greater concentration was injected. They also observed that the severity of the vacuoles was greater with higher concentrations of chondroitin sulfate. Allarakhia et al $^{12}$ also showed the appearance of peripheral lens vacuoles when Viscoat ${ }^{\circledR}$ was injected into the anterior chamber of phakic New Zealand white rabbits; the concentration and electrical charge of chondroitin sulfate $(4 \%)$ in Viscoat ${ }^{\circledR}$ were believed toxic to the crystalline lens.

In conclusion, the authors recommend use of the described test beacuse of the widespread use of viscoelastic agents and irrigation fluids in phakic eyes. The lens may be exposed to possible toxic effects with the use of such materials during penetrating keratoplasty, glaucoma surgery, trauma surgery and a host of posterior segment procedures, including vitrectomy. The lens changes may be minimal and transient but may lead to long term cataractogenic effects. In addition to this lens test, we suggest that possible toxicity to the conjunctiva, cornea, iris, and trabecular meshwork be recorded using the McDonald-Shadduck scoring system and corneal endothelial specular microscopy, corneal pachymetry, and applanation tonometry be performed to enable a comprehensive evaluation of a test material for eventual clinical use in humans.

\footnotetext{
References

${ }^{1}$ Friedenwald JS, Hughes WF, Herrmann H: Acidbase tolerance of the cornea. Arch Ophthalmol 1944, 31: 279-83.

${ }^{2}$ McDonald TO and Shadduck JA: Eye irrigation: Advances in Modern Toxicology, Vol. 4, Derma-
} 
totoxicology and Pharmacology, 1977, pp 162-166.

${ }^{3}$ McDonald TO, Britton B, Kasten K, et al.: Reproducibility of ocular scores in experimental animals. Invest Ophthamol 1975, 14(S): 108.

${ }^{4}$ Edelhauser HF, Van Horn DL, Hynduik RA, et al.: Intraocular irrigating solutions: their effect on the corneal endothelium. Arch Ophthalmol 1975, 93: 648.

${ }^{5}$ Edelhauser HF, Van Horn DL, Schultz RO, et al.: Comparative toxicity of intraocular irrigating solutions on the corneal endothelium. Am JOphthalmol 1976, 81: 473.

${ }^{6}$ McCarey BE, Edelhauser HF, Van Horn D: Functional and structural changes in the corneal endothelium during in-vitro perfusion. Invest Ophthalmol 1973, 12: 410-17.

${ }^{7}$ Haimann MH, Abrams GW, Edelhauser HF, et al. : The effect of intraocular irrigating solutions on lens clarity in normal and diabetic rabbits. Am J Ophthalmol 1982, 94: 594-605.
${ }^{8}$ Fechner PU: Preparation of $2 \%$ hydroxypropylmethylcellulose for viscous surgery. Am Intraocular Implant Soc J 1985, 11: 606-7.

${ }^{9}$ Edelhauser HF, Hanneken AM, Pederson HJ, Van Horn DL: Osmotic tolerance of rabbit and human corneal endothelium. Arch Ophthalmol 1981, 99: 1281-7.

${ }^{10}$ Gonnering R, Edelhauser HF, Van Horn DL, Durant W: The $\mathrm{pH}$ tolerance of rabbit and human corneal endothelium. Invest Ophthalmol Visual Sci 1979, 18: 373-90.

${ }^{11}$ Killey F, Spencer J, Shimuzu C, Clark D: Effects of chondrotin sulfate in rabbit eyes. Invest Ophthalmol Vis Sci 1983, 24(S):286.

${ }^{12}$ Allarakhia L, Skelnik DL, Stangler RA, Chòpp TM, Lindstrom RL: A comparative evaluation of toxicity, inflammation and intraocular pressure response of viscoelastic agents: Amvisc, Healon, methylcellulose, and Viscoat in the rabbit model. Presented at the annual meeting of the American Society of Cataract \& Refractive Surgery, April 1987, Orlando, Florida. 